\title{
As origens históricas da Clínica e suas implicações sobre a abordagem dos problemas psicológicos na prática médica
}

The historical development of modern medicine: implications for an approach to psychological problems in the medical practice

Fernando Antônio Mourão Flora*

\section{RESUMO}

Os problemas psicológicos são muito comuns nos consultórios dos médicos generalistas. Incluem, pela incidência, os transtornos somatomorfos e os episódios depressivos com sintomas somáticos. Esses distúrbios não apresentam nenhuma patologia orgânica. A Clínica foi, em seus primórdios, classificadora. A doença recebeu uma organização hierarquizada em famílias, gêneros e espécies. O papel do médico era o de descobrir a doença no doente. A doença se apresentava segundo os sintomas e os sinais. A Clínica baseava-se na anatomia patológica e na fisiopatologia. Devido a esta longa tradição secular, que o condicionou a investigar o "orgânico", o médico não está preparado para cuidar de pacientes com problemas psicológicos. Isso porque não encontra o substrato anátomo e fisiopatológico a que foi exercitado a descobrir. Uma proposta para capacitar o médico generalista a lidar com as emoções na prática médica é o "grupo Balint". Trata-se de um método de capacitação em seminários de grupo, com sessões semanais e duração de dois anos, fundamentado em apresentação de casos. O objetivo é obter uma mudança de personalidade do generalista, limitada, porém significativa, de maneira a habilitá-lo a cuidar de seus pacientes com problemas psicológicos.

\section{ABSTRACT}

Patients with psychological problems are very common in the offices of general practitioners. Grouped according to their incidence these problems include somatoform disorders and episodes of depression with somatic symptoms. These disorders have no organic basis or known physiological cause. In its early beginnings, medicine and medical regard were classificatory. Disease was organized hierachically into families,

PALAVRAS-CHAVE:

- Medicina Clínica;

- Relação Médico-Paciente;

- Somatização;
PALAVRAS CHAVE:

- Clinical Medicine;

- Physician-Patient Relations;

- Somatoform disorders.

*Médico, Mestre em Saúde Pública, SMS Belo Horizonte, MG, Brasil.

203 Rev Bras Med Fam e Com

Rio de Janeiro, v.2, $\mathrm{n}^{\circ} 7$, out/dez 2006 
genera and species. The role of the physician was to discover the patient's disease. The disease presented itself through symptoms and signs. Medical practice was based on anatomical pathology and physiopathology. Due to this secular tradition during which he was conditioned to investigate the "organic", the physician is not prepared for providing care to patients whose problems are of psychological nature. The anatomical and physiopathological substrate he was trained to discover is lacking.

The "Balint group" represents a proposal for capacitating the general practitioner for dealing with the emotional in his medical practice. This is done in two-weekly seminars during a two-years' period, based on case reports. The objective of this initiative is to provoke a limited but significant change in the personality of the general practitioner for enabling him to provide care to his patients presenting with psychological problems.

\section{Introdução}

Um paciente chega à consulta do generalista com o problema de distúrbios neurovegetativos que o impedem de adormecer; outro se queixa de fraqueza, perda de peso e de apetite. Em um atendimento de urgência, uma cliente apresenta uma "dramática" dispnéia, simulando uma crise de asma. Os exemplos poderiam multiplicar-se indefinidamente. Esse é o cotidiano do médico: uma parte de seus pacientes apresenta uma sintomatologia em que não é detectada nenhuma patologia orgânica. Muitas vezes, o médico considera que esses pacientes "não têm nada"1 ou que são pessoas "nervosas", cujas doenças estão "em suas cabeças"2. A peça teatral $O$ doente imaginário, de Molière, é uma sátira deste tipo de patologia.
Nos exemplos citados acima, o paciente com distúrbio neurovegetativo é um homem de meia-idade com problemas financeiros, a senhora emagrecida perdeu seus sobrinhos, assassinados, e a cliente dispnéica está em uma crise conjugal devido à infidelidade do marido. Portanto, são pacientes que se consideram doentes fisicamente, mas que, inconscientemente, apresentam problemas psicológicos como causa de seus sintomas.

As estimativas variam; todavia, calcula-se que entre um quarto e um terço dos pacientes que recorrem ao generalista estão em uma condição de estresse psicossocial ${ }^{3}$. O que se constata é que o médico não está preparado para atender a estes casos nem sabe qual conduta adotar ${ }^{2,4}$.

Procuremos, inicialmente, delimitar este contingente de pacientes. Pode-se entender por "problemas psicológicos" na prática médica uma ampla rede de patologias, que abarca, pela incidência, os transtornos somatomorfos e os episódios depressivos com sintomas somáticos ${ }^{5,6}$. Trata-se de uma série significativa de patologias atribuídas à influência exercida sobre o corpo pelas emoções ${ }^{7}$.

Um expressivo número de indivíduos rotulados como nervosos, neurastênicos, psicastênicos, histéricos, neuróticos e psicopatas, doentes funcionais, doentes psicógenos, doentes psicossomáticos pode apresentar distúrbios funcionais 8 .

Detenhamo-nos aos transtornos somatomorfos pelo seu mimetismo com as doenças físicas ${ }^{5}$. Incluem o transtorno de somatização, o transtorno conversivo, o transtorno doloroso, a hipocondria e o transtorno dismórfico corporal ${ }^{7,9}$.

Segundo H. J. Weitbrecht ${ }^{8}$, os transtornos somatomorfos (ou funcionais) do organismo compõem um grupo heterogêneo de distúrbios que não 
apresenta nenhuma patologia orgânica. O primário nestes pacientes é uma atitude ou desenvolvimento psíquico anormais, que secundariamente dão lugar a disfunções vegetativas, vasculares ou neuroendócrinas.

Os transtornos somatomorfos situam-se na fronteira da Medicina e da Psiquiatria. Possuem os atributos seguintes: (a) a tendência do paciente a "experienciar" e a comunicar sintomas somáticos; (b) os sintomas não são sustentados por achados patológicos; (c) o paciente atribui suas queixas a uma doença física; (d) o paciente procura ajuda médica para os sintomas; (e) o estresse psicossocial, assim como a vulnerabilidade da personalidade ao estresse, pode ser uma característica associada (embora o paciente não reconheça e até mesmo negue qualquer ligação entre os sintomas e causas psicológicas). $\mathrm{O}$ denominador comum desses distúrbios é que tendem a se manifestar como se a anatomia não existisse ${ }^{4}$.

A maioria destes pacientes é vista e tratada sintomaticamente por médicos generalistas, por especialistas (não-psiquiatras) ou por adeptos da medicina alternativa. São muito comuns nos consultórios dos médicos generalistas. Calcula-se em um terço o número de consultas em Atenção Primária à Saúde em que nenhuma patologia orgânica é identificada (na experiência de consultório do médico de família de Waco, Texas, em uma amostra de 1.073 pacientes foram identificados $120 \mathrm{com}$ transtornos somatomorfos) $)^{3}$.

Existe o risco de diagnosticar erroneamente um transtorno funcional neurótico onde na realidade existe uma doença orgânica. Não é fácil fazer o diagnóstico de transtorno somatomorfo. É evocado pelo generalista quando o paciente apresenta, repetidamente, queixas vagas e variadas, sem uma etiologia estabelecida. Esses pacientes requerem mais tempo de consulta e são considerados "difíceis", ou no termo em inglês, doctor shoppers ${ }^{1}$.

Esses problemas clínicos, pois, são freqüentes e associados com altos custos diretos e indiretos. Os pacientes com transtornos somatomorfos são submetidos a uma enorme bateria de exames complementares e procedimentos diagnósticos inúteis. Os resultados falso-positivos podem levar a tratamentos equivocados, complicações, morbidade desnecessária e desperdícios ${ }^{7}$.

Por se situarem na fronteira entre disciplinas, existe pouca pesquisa sobre o diagnóstico e o tratamento dos transtornos somatomorfos. A avaliação de seu tratamento pelo generalista pode ser considerada como insatisfatória ${ }^{3}$. Os médicos centram-se no alívio dos sintomas, por meio da prescrição de medicamentos, como é o procedimento padrão. Várias tentativas terapêuticas acabam não dando resultado, frustrando o médico e o paciente ${ }^{10,11}$.

A questão a ser elucidada neste artigo referese à abordagem dos problemas psicológicos (em sentido genérico) na prática médica e a falta de preparo dos generalistas para abordá-los. Assim, a primeira pergunta a ser respondida é explicar por que o generalista está despreparado para lidar com estas patologias de fundo emocional, tão freqüentes em sua prática. O meio para decifrar este paradoxo será a análise de discurso do ensaio O Nascimento da Clínica, do filósofo estruturalista Michel Foucault.

Uma vez explicado o paradoxo, o ponto é como capacitá-lo para cuidar dos clientes com esses distúrbios. Por fim analisa-se o método Balint como estratégia para habilitar os generalistas no manejo dos problemas psicológicos de seus clientes. 


\section{O Nascimento da Clínica}

O médico, condicionado a se ocupar do "orgânico" por uma longa tradição secular, não está preparado na sua prática cotidiana para lidar com os problemas psicológicos de seus pacientes. Isso porque não encontra o substrato anátomo e fisiopatológico a que foi exercitado a descobrir. É costume, então, emitir o seguinte juízo, eivado de conseqüências: "O doente não tem nada". Somente é possível entender esta postura à luz da história da estruturação da Clínica através do tempo.

O Nascimento da Clínica é o título do livro do filósofo Michel Foucault ${ }^{12}$ que faz um estudo arqueológico do saber médico ocidental, por meio de uma análise estrutural de seus textos. Procedemos a um sumário de sua obra, apresentada a seguir.

Desde a Renascença, ocorreu uma mudança na tradição médica, que vinha desde o século $V$, na Grécia, com a longa história dos sistemas, ou seja, da influência da metafísica. Pode-se situar o nascimento da medicina moderna no final do século XVIII. Passou-se a privilegiar o empírico (a percepção) e a razão, com o abandono das teorias, dos velhos sistemas e de suas especulações imaginárias. A experiência clínica pôs por terra o dogma aristotélico e iniciou o discurso científico.

Nos seus primórdios, esta medicina era classificatória. A experiência médica do século XVIII ocupou-se, constitucionalmente, de organizar um campo nosológico. Estudava-se "a maneira como a natureza produz e entretém as diferentes formas de doenças", no dizer de Sydenham ${ }^{13}$. A doença recebeu uma organização hierarquizada em famílias, gêneros e espécies. Frier ${ }^{14}$ ensinava: "O conhecimento das doenças é a bússola do médico; o sucesso da cura depende de um conhecimento exato da doença".
A medicina das espécies patológicas considerava o hospital um lugar artificial, onde a doença alojada incidia no risco de perder suas características originais. Ela podia sofrer toda forma de complicação, que os médicos chamavam de "febre" dos hospitais ou das prisões. O lugar natural da doença era o da vida: a família. Diferente do internista, que lidava com doenças desfiguradas, o médico que tratava em domicílio "adquire em pouco tempo uma verdadeira experiência, fundada sobre os fenômenos naturais de todas as espécies de doenças"15. O papel do médico era o de descobrir a doença no doente, escondida nele como um criptograma. A doença possuía uma organização que the era própria. O doente era um "acidente" da doença, o objeto transitório do qual ela se apossava. Segundo Cabanis ${ }^{16}$ : "as diferentes doenças servem de texto". O doente era o veículo por meio do qual este texto se exprimia, às vezes de forma complicada e embaralhada. Girbal descrevia o domínio clínico ${ }^{17}$ :

"Esclarecer o princípio e a causa de uma doença através da confusão e da obscuridade dos sintomas; conhecer sua natureza, suas formas, suas complicações; distinguir na primeira olhada todas as suas características e todas as diferenças [...]".

O exame clínico procurava estabelecer a relação entre os fenômenos, os antecedentes e os distúrbios constatados, de forma a poder pronunciar um nome: o da doença. Uma vez feita essa designação, deduzia-se facilmente as causas, o prognóstico, as indicações. Tratava-se, portanto, da descoberta de uma "verdade", escondida, já presente no corpo do doente: o nome da doença.

A clínica consistia na arte de "demonstrar mostrando". Cabanis ${ }^{18}$ assim explicava o ensino médico: "O professor indica a seus alunos a ordem pela 
qual os objetos devem ser observados, para serem melhores percebidos e gravados na memória". Acompanhe-se a descrição das aulas de clínica cirúrgica de Desault, em 1781, no Hôtel-Dieu:

"Sob os olhos de seus expectadores, fazia trazer os doentes mais graves, classificava suas doenças, analisava as características, definia a conduta a ser adotada, praticava as cirurgias necessárias, prestava conta dos seus procedimentos e de seus motivos, mostrava as mudanças diárias e apresentava o estado das partes após a cura... ou demonstrava sobre o corpo privado de vida as alterações que haviam tornado a arte inútil" ${ }^{19}$.

Desde a Renascença, a Clínica foi, provavelmente, a primeira tentativa para fundar uma ciência fundamentada unicamente no campo perceptivo e uma prática guiada pelo exercício do olhar. Segundo Petit ${ }^{20}$ : "É preciso, tanto quanto possível, tornar a ciência ocular". Na tradição médica do século XVIII, a doença se apresentava ao observador segundo os sintomas e sinais.

O sintoma ocupava um lugar especial porque era a forma sob a qual se apresentava a doença. De tudo o que era visível, era o mais próximo do essencial e era a primeira transcrição da natureza inacessível da doença. Os sintomas deixavam transparecer a figura invariável, retraída, visível e invisível da doença. Para Broussonnet ${ }^{21}$ :

"Nós entendemos por fenômeno, toda mudança notável do corpo sadio ou doente; daí a divisão entre aqueles que pertencem à saúde e os que designam a doença: estes últimos confundem-se facilmente com os sintomas ou aparências sensiveis da doença".

Por essa simples oposição às formas da saúde, o sintoma deixava de ser um fenômeno natural passivo e tornava-se representação da doença.

A clínica supunha a visibilidade da doença, o olhar e o objeto entrelaçados pela natureza e pela origem. Era o olhar médico que abria o segredo da doença e era essa visibilidade que a tornava penetrável à percepção. O olhar que observava evitava intervir: era mudo e sem gesto. A pureza do olhar do clínico estava ligada a certo silêncio que permitia escutar: "Toda teoria silencia ou sempre some ao pé do leito do doente", na expressão de Corvisart ${ }^{22}$. Também devia ser contido o imaginário, que antecipava sobre o que se percebia, descobria relações ilusórias e fazia falar o que era inacessível aos sentidos. O olhar clínico tinha esta propriedade paradoxal de ler a natureza no momento em que percebia um espetáculo. Pinel ${ }^{23}$ assim o descrevia:

"Os sinais exteriores pegos do estado do pulso, do calor, da respiração, das funções de raciocínio, de alteração dos traços do rosto, das afecções nervosas ou espasmódicas, da lesão dos apetites naturais, formam, por suas diversas combinações, quadros diversos, mais ou menos distintos ou claramente delimitados [...]. A doença deve ser considerada como um todo indivisível, desde o seu início até o seu término, um conjunto regular de sintomas característicos e uma sucessão de períodos".

O exercício da observação clínica abria um novo espaço: o espaço concreto do corpo, massa opaca onde se escondiam segredos, lesões invisíveis e o mistério mesmo da vida. A medicina dos sintomas engendrou aquela dos órgãos e das causas, uma clínica com base na anatomia patológica, a idade de Bichat.

A Medicina só podia ter acesso ao que a fundava cientificamente, contornando, com lentidão, os obstáculos da religião, da moral e dos preconceitos. 
Isso até se admitir que o cadáver fazia parte, sem contestação religiosa ou moral, do campo da Medicina. Morgagni, na metade do século XVIII, não teve dificuldades para fazer suas autópsias. Como o Sepulchretum (Bonet, 1700), o tratado de Morgagni (De sedibus, 1760) procurava estabelecer que a anatomia patológica fundava a Clínica, que as lesões explicavam os sintomas. A concepção era de que a anatomia definia a forma fundamental da espacialização local e, por uma relação de contigüidade, as vias da comunicação fisiológica ou patológica.

A maior descoberta de Bichat foi um princípio para decifrar o espaço corporal, que era ao mesmo tempo intra, inter e trans-orgânico. O elemento anatômico foi deslocado de sua condição primeira na espacialização, que passou a ser o tecido. Bichat ${ }^{24}$ comparava a sua descoberta com a de Lavoisier:

"A química tem seus corpos simples que formam compostos pelas combinações diversas possíveis [...]. Igualmente, a anatomia tem seus tecidos simples que [...] por suas combinações formam os órgãos".

Os diferentes tecidos eram as matériasprimas dos órgãos, mas os ultrapassavam, formando vastos sistemas nos quais o corpo humano encontrava sua unidade concreta. A análise tecidual de Bichat tornava possivel estabelecer formas patológicas gerais, para além das repartições geográficas de Morgagni. A anatomia patológica tinha construído um fundamento sólido: a análise real segundo superfícies perceptíveis. Desenhavam-se, por meio de uma leitura diagonal do corpo, grandes famílias de doenças, tendo os mesmos sintomas maiores e o mesmo tipo de evolução. Alcançava-se, enfim, um fundamento objetivo, real e indiscutível, de uma descrição das doenças: "Uma nosografia baseada na alteração dos órgãos será necessariamente invariável” ${ }^{25}$. Da mesma forma que as nosologias tradicionais começavam por uma definição das classes mais gerais, a anatomia patológica lançava as bases de uma história das alterações comuns a cada sistema, quaisquer que fossem os órgãos ou as regiões afetadas.

A questão era como ajustar a percepção anatômica à leitura dos sintomas. Corvisart buscava a confirmação da nosologia pela autópsia: era preciso "comparar sempre os fenômenos sensíveis e próprios da vida saudável de cada órgão, com as alterações que cada um deles apresenta na sua lesão"22. Laënnec ${ }^{26}$ seguia a direção inversa:

"A anatomia patológica é uma ciência que tem por objetivo o conhecimento das alterações visíveis que o estado doentio produz sobre os órgãos do corpo humano. A abertura de cadáveres é o meio de adquirir este conhecimento; mas para que tenha uma utilidade direta [...] é preciso juntar a observação dos sintomas ou as alterações de funções que coincidem com cada espécie de alterações de órgãos".

Com a anatomia patológica, a relação médicopaciente tornou-se uma experiência na qual o olhar do médico era o elemento decisivo do espaço patológico e de sua armação interna. O contato não era possível senão sobre o fundo de uma estrutura, na qual o medical e o patológico se entrelaçavam, do interior, na plenitude do organismo. A medicina e a cirurgia não eram mais que uma só e mesma coisa, na medida em que o deciframento dos sintomas se ajustava à leitura das lesões.

O olhar médico passou por uma verdadeira "revolução" (a medicina das reações patológicas) com o tratado de Broussais, em 1816, Examen de la doctrine ${ }^{27}$. Nele foi exposto um método clínico aplicado ao agravo orgânico, que propunha "extrair da fisiologia 
os traços característicos das doenças e discernir, por uma análise cuidadosa, os apelos muitas vezes confusos dos órgãos doentes". Esta medicina de órgãos afetados comportava três momentos: 1) determinar qual órgão estava em sofrimento, o que se faz a partir dos sintomas manifestos; 2) "Explicar como um órgão entra em sofrimento" e 3) "Indicar o que é preciso fazer para que deixe de sofrer". Broussais tinha fixado o último elemento da "maneira de ver" do clínico.

A evolução histórica e concreta do olhar médico moderno havia acabado a sua estruturação.

\section{A tradição clínica e os seus efeitos}

Vamos revisitar o texto de Foucault e procurar extrair, a partir da proto-clínica do século XVIII, os efeitos sob o conhecimento, as habilidades e as atitudes do médico nos dias de hoje.

Vimos que, na Renascença, ocorreu uma verdadeira mutação do saber médico, com a recusa das teorias, o abandono dos velhos sistemas e da metafísica da Idade Média. Em seu lugar, passou-se a valorizar o empírico, a experiência clínica. Era o início da Ciência moderna, que nos dias atuais tem sua expressão mais estruturada na chamada Medicina Baseada em Evidência. O termo evidência expressa o que é comprovado cientificamente, o que é demonstrado experimentalmente.

Essa é a habilidade essencial que foi transmitida desde os primórdios da Clínica: observar as evidências, o que pode ser percebido. A advertência subtendida nesta instrução é de que devem ser contidos: o imaginário, a teoria, o que é inacessível aos sentidos. A prática deve ter base no exercício do "olhar".

Isso está emblematicamente expresso na chamada "Observação clínica", o roteiro de sistematização das informações sobre o paciente, por meio de seu depoimento a respeito de seu estado interior, o interrogatório de seus antecedentes patológicos e familiares, de seu perfil pessoal, dos diversos apareIhos do organismo, o exame físico e os exames complementares. Nas palavras de Sournia ${ }^{28}$ :

"Para poder propor a cada um de nossos doentes um tratamento perfeitamente adaptado à sua doença e a ele mesmo, nós procuramos ter uma idéia objetiva e completa de seu caso, reunimos num prontuário que Ihe é pessoal (sua "observação") a totalidade de informações que dispomos sobre ele. Nós o "observamos" da mesma maneira que nós observamos os astros ou uma experiência de laboratório".

O olhar clínico, além de herdar uma "ordem pela qual os objetos devem ser observados para serem melhor percebidos e gravados na memória", prossegue com o hábito de recolher os sinais e os sintomas da doença. O doente é a fonte primária das informações, que são processadas pelo observador. Seu discurso dá acesso à percepção que possui do próprio corpo e de suas alterações. O exame "físico" (em inglês, médico é physician), método de investigação do espaço concreto do corpo, guarda toda sua centralidade enquanto exercício da habilidade do clínico na identificação dos sinais patológicos, mesmo com todos os avanços científicos dos exames complementares. É uma etapa indispensável da experiência clínica, usando praticamente os mesmos meios que a invenção de Laënnec ${ }^{29}$.

No plano do conhecimento, a influência da medicina classificadora, calcada no modelo botânico, perpetuou-se até hoje. O conhecimento das doenças, apesar do acúmulo de informações, é um saber indispensável para o clínico. O trabalho investigativo, desde o primeiro olhar sobre a aparência do paciente, desencadeia o raciocínio clínico e constitui um "vai e vem" 
entre as informações colhidas e a memória do aprendido pelo médico. Cada caso é a montagem de um quebra-cabeças e, com o auxílio de um raciocínio hipotético-dedutivo, o clínico vai estabelecendo a relação entre os fenômenos, comparando com o que sabe, até descobrir a doença, nomear o diagnóstico e estabelecer a terapêutica ${ }^{30}$.

A atitude do médico foi se cristalizando até chegar ao papel social de um observador neutro, com a atenção voltada para a doença e os seus múltiplos disfarces. Este investigador das pistas que o levam a identificar o mal que acomete o doente, incorre, por vezes, no erro de "esquecer" a pessoa por trás da doença. Tal é o risco a que o expõe o personagem que encarna, e que foi moldado através de, pelo menos, três séculos.

Então, o médico adquiriu uma segunda natureza que o condicionou a aceitar somente o que passa pelo crível do empírico, da percepção. Uma das mais poderosas influências que herdou foi a valorização do conhecimento extraído da morte e consubstanciado na anatomia patológica. A autópsia permitiu que o olhar clínico penetrasse no espaço interno do corpo, para assim constatar as lesões nos órgãos.

Chegamos, pois, ao comentário de Foucault: “o cadáver aberto e exteriorizado é a verdade interior da doença, é a profundidade exposta da relação médico-paciente"12. Nele estão sintetizados os principais efeitos da tradição clínica sob o médico de hoje: a habilidade aguçada da percepção (o olhar clínico), o conhecimento racional do "espetáculo" da doença, em toda a sua crueza concreta ("orgânico"), e a atitude neutra de observador/investigador dos fenômenos patológicos do corpo humano.

\section{O doutor, o seu paciente e a doença}

Os médicos foram habilitados para lidar com os distúrbios orgânicos; quando se deparam com as dificuldades emocionais de seus pacientes, encontram-se despreparados para abordá-las. Esta é a necessidade que levou aos seminários sobre "problemas psicológicos em Medicina Clínica", organizados pelo pioneiro, Dr. Michael Balint, psiquiatra e psicanalista.

Vejamos os resultados da investigação sobre este tema, efetuada por Balint e compilada em sua obra: O Doutor, o seu Paciente e a Doença ${ }^{31}$. Esta pesquisa levou mais de cinco anos, iniciando-se em 1952, na Tavistock Clinic (Londres), e realizada com 14 generalistas.

A constatação inicial foi a mesma que já tinha sido feita nos primórdios da Clínica: existe uma clivagem entre a ciência médica tal como é exercida nos hospitais e a prática geral que se faz no consultório do generalista.

Os especialistas-professores dos generalistas nas escolas de Medicina inclinam-se a diagnosticar patologias no âmbito de suas especialidades, até porque não atendem longitudinalmente. As doenças descritas pelos "rótulos" da medicina hospitalar, nestes casos, não ajudam o generalista a compreender os verdadeiros problemas com os quais se defronta.

Nos consultórios dos generalistas, os problemas dos pacientes apresentam-se, muitas vezes, sob a forma de "uma doença da pessoa inteira". Os casos analisados revelam que algumas pessoas não conseguem enfrentar as dificuldades de suas vidas e "fogem" ficando doentes.

A estimativa é de que pelo menos um quarto dos pacientes consultados sejam casos psicológicos. Se o médico tem a oportunidade de vê-los no início do processo patológico, pode perceber que tais pa- 
cientes "oferecem" ou propõem diversas doenças, até que se fixam a uma doença precisa e "organizada". No entanto, os generalistas, influenciados pelos especialistas, evocam preliminarmente um diagnóstico "orgânico", mesmo quando as evidências apontam para um problema psicológico. Os médicos consideram que a doença física é mais séria e perigosa que uma doença funcional. Conhecem mais as patologias orgânicas e, então, sentem-se seguros, em um terreno mais firme do que quando se deparam com alterações funcionais ou psíquicas. As doenças são catalogadas em uma sorte de classificação hierárquica, correspondendo à gravidade das lesões anatomopatológicas.

Cada médico tem um modelo ideal do comportamento que deve adotar uma pessoa quando está doente. Esta missão ou "função apostólica" se expressa em sua conduta. Trata-se da tendência do médico de alimentar expectativas ilusórias sobre o paciente, com base em seus próprios valores. Espera enquadrá-lo em um diagnóstico e "convertê-lo" às virtudes da medicalização.

O roteiro habitual seguido pelo generalista é dominado pelo medo de deixar passar alguma doença física. O receio é o de fazer um diagnóstico de transtorno funcional neurótico onde possa existir uma doença orgânica. Utiliza-se de duas estratégias securizantes: os exames complementares e a referência a especialistas.

A "eliminação por exames físicos apropriados" constitui uma rotina obrigatória na prática diária. $\mathrm{O}$ método de escolha é pedir exames complementares à exaustão, até que um sinal físico acidental, e muitas vezes sem significação, possa ser responsabilizado pela sintomatologia. Esta "resposta" do médico tem a conseqüência iatrogênica de induzir, levar, o paci- ente a "organizar" a sua doença em torno do desvio encontrado. O passo seguinte será convencer o paciente da utilidade da prescrição para os seus sintomas, embora precise de algo diferente.

O outro recurso utilizado pelo generalista diante de um "caso difícil" é o de encaminhar o paciente ao(s) especialista(s) para um diagnóstico mais preciso ("perpetuação da relação professoraluno"). Em toda situação deste tipo, em que o doente "oferece" uma doença "atípica" ao generalista, levando-o a pedir ajuda ao especialista, ocorre uma "colusão no anonimato" ou de "diluição de responsabilidades". O sentido desta expressão é a de que o paciente pode ser referenciado a diferentes especialistas, sem que ninguém assuma a responsabilidade por ele enquanto pessoa. $\mathrm{O}$ doente vira um prontuário impessoal, freqüentemente circulando entre diferentes especialistas, que também se confundem diante de um quadro rebelde a se encaixar nos rótulos ou esquemas. O generalista, que não deveria deixar de conhecer as conseqüências das condutas dos especialistas, acaba por delegar suas responsabilidades. Assim, podem ser tomadas decisões vitais - às vezes após terem sido consultados diferentes especialistas -, sem que ninguém se sinta plenamente responsável.

Os doentes cujos distúrbios possam ser atribuídos a prováveis alterações anatômicas e fisiológicas são de uma categoria superior, enquanto os neuróticos engrossam o contingente do que sobrou, uma vez realizado o diagnóstico diferencial. O generalista orgulha-se de ter despistado uma doença física, mas incomoda-o defrontar-se com uma neurose. Está despreparado para lidar com os problemas psicológicos. Diante da angústia e da pressão crescente do paciente, pode mesmo se sentir culpado: seus exa- 
mes mais criteriosos não esclareceram a "doença" e o tratamento atualizado que instituiu, não trouxe o alívio esperado. O paciente, por sua parte, quer saber o nome da sua doença, o diagnóstico, a razão da medicação não ter funcionado. Diante desta demanda, recebe como resposta que "nada tem", o que equivale a ter a sua "oferta" rejeitada e a ficar com o seu problema não resolvido.

A solução de Balint já estava contida em sua tese inicial, exposta acima: "Nós pensamos que certas pessoas que, por uma razão ou por outra, não podem enfrentar os problemas de suas vidas se livram ficando doentes" ${ }^{31}$.

O generalista deve ter discernimento para saber quais são os casos em que é essencial tratar uma doença física e em quais ele precisa ajudar o paciente a assumir os seus problemas pessoais.

Para chegar ao nível de desvelar o que está oculto, é preciso que o generalista proceda a um diagnóstico "aprofundado", isto é, que contemple os problemas da personalidade global. A metodologia a seguir, "a entrevista prolongada", implica na habilidade da "escuta" por parte do médico.

É necessário ampliar os limites da anamnese padrão, sem deixar de reconhecer o valor das informações pertinentes assim obtidas, porque "aquele que faz perguntas obtém respostas, mas nada além disso".

O generalista responsável pelo paciente deve estar em condições de acompanhar o curso de sua história de vida, de forma a poder contextualizar uma eventual doença psicológica. Só assim pode alcançar uma ampla compreensão das "ofertas" de seus pacientes, ou seja, fazer um diagnóstico "aprofundado". Trata-se de bem "administrar" o "fundo mútuo de investimento", isto é, todas as experiências e a confiança compartilhadas entre o médico e o paciente, que foram acumuladas, às vezes, durante anos de convívio.

O "remédio médico", sendo o doutor em si mesmo uma poderosa "medicação", é o "medicamento" mais usado na prática, mas pode ser decisivo para a cura naqueles episódios em fases precoces “desorganizadas". Muitos casos poderão ser solucionados nesses estágios, tornando desnecessário o encaminhamento para psicoterapia com um psicoterapeuta. Trata-se, de fato, de uma psicoterapia breve, em que o médico aprende a se servir de si mesmo como instrumento terapêutico, assim como um cirurgião usa um bisturi.

Resta abordar a questão de como os generalistas podem adquirir o mínimo de aptidões para lidar com as emoções de seus clientes.

Comecemos por compreender por que, psicologicamente, evitam explorá-las. Deixemos de lado a questão de sua formação voltada para o "orgânico" ou a sua falta de preparo para lidar com as emoções. A explicação do autor é que, quando uma pessoa está doente fisicamente, o clínico está em uma situação diferente e distante de sua condição, embora se solidarize com ela. Mas, quando o paciente está infeliz em sua relação com o mundo, o médico pode sentirse pessoalmente implicado, devido a seus próprios problemas. Procura, a partir daí, evitar situações que poderiam levá-lo a examinar os seus conflitos pessoais.

Segue-se que o generalista tem a necessidade de "uma mudança de personalidade considerável, ainda que limitada". Como obtê-la?

Balint propõe como método seminários de grupo, de oito generalistas coordenados por um psiquiatra/psicanalista, em encontros semanais. $\mathrm{O}$ 
número foi fixado para proporcionar uma participação intensa e um material suficientemente diversificado. Isso porque se trata de provocar uma nova atitude no médico, o que implica em expô-lo à situação real e levá-lo a reconhecer os problemas e as formas que podem ser empregadas para tratá-los. As discussões semanais de casos são as matérias-primas para a da relação de cada generalista com os seus clientes. É possibilitado ao generalista, sob demanda, uma supervisão individual de seus casos, ou seja, uma hora por semana de "entrevista particular".

Um dos objetivos é o de desenvolver nos médicos a sensibilidade diante dos problemas emocionais de seus pacientes, de modo que possam compreendê-los melhor e com maior profundidade. Um outro é ajudá-los a aprender a empregar esta compreensão de forma a obter um efeito terapêutico. Para alcançar esses fins, é indispensável modificar a personalidade do médico, particularmente quando atua no exercício profissional. Deve aprender a perceber e a tolerar os fatores emocionais de seus pacientes, que antes rejeitava ou ignorava, além de aceitá-los como dignos de sua atenção. Balint chamou a totalidade deste processo como "mudança de personalidade limitada, todavia significativa".

A essência do método de capacitação, o "grupo Balint ${ }^{32}$, é fazer com que o médico tome consciência de toda sua responsabilidade terapêutica, cerceando-Ihe qualquer rota de fuga; comparar sua maneira de tratar a seus pacientes com a de outros colegas do seminário; utilizar o grupo para demonstrar que toda terapia necessariamente implica um tipo específico de interação entre o paciente e o médico.

O foco está centrado no subjetivo e pessoal, muitas vezes fora do controle consciente. O mais importante nos seminários de grupo é a análise da relação médico-paciente, das emoções na interação. É a chamada "contratransferência", isto é, a forma como o generalista utiliza sua personalidade, suas crenças, seu saber, seus modos habituais de reação etc. As discussões dos seminários fornecem o motor da "mudança de personalidade considerável, ainda que limitada". O que se produz durante os seminários é que o generalista toma consciência de seu envolvimento pessoal e de suas resistências em suas relações com o paciente e com o resto do grupo.

Esses seminários duram dois anos, em sessões semanais, capacitando o generalista a tratar uma grande parte dos seus pacientes com problemas psicológicos. Habilitam-no a impedir, com uma intervenção precoce, o paciente de "organizar" sua doença em torno de qualquer sinal físico de pouca importância. A profundidade da penetração do generalista no conflito do paciente depende de sua própria personalidade, isto é, de sua função apostólica. Assim, pode chegar a identificar o "conflito" que levou o paciente a se queixar, descobrindo o verdadeiro problema em sua vida. Em outras palavras, o generalista é capaz de manejar com competência o "remédio médico", o "medicamento" mais freqüente da prática geral.

Por fim, conheçamos a avaliação do método dos seminários de discussão em grupo para os generalistas $^{32}$. Dentre os chamados "desertores", aqueles que abandonavam os seminários após certo tempo, podem ser descritos os seguintes grupos: os médicos que padeciam de uma patologia mental grave (neurose severa ou borderline; os "superiores", médicos prestigiosos, de profundo "fervor apostólico", como possível defesa contra a insegurança; os médicos escrupulosos e sensitivos, que necessitavam de "receitas" para as situações; os médicos com uma 
ansiedade neurótica diante da mudança; os médicos com defesas sólidas e eficazes, que preferiam evitar uma série de temas.

$\mathrm{Na}$ avaliação de Balint, os generalistas que acompanharam até o fim os seminários eram médicos "natos" ou muito talentosos, que "experienciavam" uma satisfação "profunda" no exercício profissional.

Citemos dois depoimentos de generalistas que participaram dos grupos Balint: "O maior benefício veio de escutar as estórias das relações médicopaciente contadas pelos outros participantes do grupo" ${ }^{3}$. E ainda: "Acredito que os seminários tornaram-me melhor em meu trabalho [...]. Posso afirmar que certamente me ajudaram a lidar com menos ansiedade com pessoas diferentes ou difíceis" ${ }^{34}$. Os seminários permitiram aos médicos perceber que as pessoas "difíceis" eram suas semelhantes, que estavam pedindo ajuda, e não tentando criar situações sem saída.

Todavia, o generalista precisa de pelo menos dois anos de capacitação para se beneficiar de um grupo Balint.

\section{Conclusões}

A moderna concepção sobre a etiologia das doenças é a de que muitos fatores interagem para produzi-las ${ }^{35}$. De acordo com este modelo de Engels, os fatores biopsicossociais estão envolvidos nas causas, manifestações, curso e evolução da saúde e das doenças. Os papéis relativos dos fatores biológicos, psicológicos ou sociais podem variar entre os indivíduos ou entre os períodos da duração da vida.

Procuramos demonstrar, ao longo deste trabalho, que os médicos possuem "pontos cegos" em relação aos fatores psicológicos e sociais, privilegiando os biológicos, devido à sua formação ${ }^{36}$.
Mostramos que os fatores estressantes psicológicos e sociais podem se "metamorfosear" em distúrbios somatomorfos ou outros, camuflando-se atrás dos sintomas, e que os esforços terapêuticos são de utilidade duvidosa se as verdadeiras causas não forem abordadas."Uma doença 'funcional' significa que o paciente teve um problema que tentou resolver com uma doença" ${ }^{31}$.

Os fatores estressantes psicológicos e sociais mais comuns na vida adulta abarcam a ruptura de relações afetivas íntimas, a morte de um familiar ou amigo próximo, as dificuldades econômicas, a saúde física precária e os acidentes e a violência que atingem a integridade física. Esses fatores desencadeiam distúrbios em pessoas vulneráveis, isto é, com maior risco de adoecer.

Propusemos o grupo Balint como um método que capacita o médico generalista a lidar com as emoções na prática médica, por meio de uma "pequena", mas significativa mudança de personalidade" 32 . O objetivo é que saiba se servir do "remédio médico", ou seja, de si mesmo, na relação com o paciente.

\section{Referências}

1.Koyazu T. Schematic understanding of the worried patient with somatoform disorder. In: On Y. (Eds.) Somatoform Disorders. A Worldwide Perspective. Keio University: Springer; 1999. p.218-221.

2.Kirmayer LJ. Rhetorics of the body: medically unexplained symptoms in sociocultural perspective. In: Ono Y. (Eds.) Somatoform Disorders. A Worldwide Perspective. Keio University: Springer; 1999. p. 271-283. 3.Couchman G. Approach to the treatment of somatoform disorders in general practice. In: Ono Y. (Eds.) Somatoform Disorders. A Worldwide Perspective. Keio University: Springer; 1999. p. 229-231. 
4.Jablensky A. The concept of somatoform disorders: a comment on the mind-body problem in psychiatry. In: Ono Y. (Eds.) Somatoform Disorders. A Worldwide Perspective. Keio University: Springer; 1999. p. 3-10. 5.Tierney Jr LM, McPhee SJ, Papadakis MA. Medical Diagnosis \& Treatment. $35^{*}$ ed. Stamford: Lange Medical Publications; 1996. p.924-7.

6. Hoff H, Ringel E. Problemas generales de la medicina psicosomatica. Madrid. Ediciones Morata; 1969.

7.Frances $A$, Vance $B$. The differential diagnosis of somatoform disorders. In: Ono Y. (Eds.) Somatoform Disorders. A Worldwide Perspective. Keio University: Springer; 1999. p. 19-25.

8.Weitbrecht HJ. Errores del diagnóstico psiquiátrico en la práctica médica. Barcelona: Ediciones Toray; 1968. p.134-167.

9.Barsky AJ. Hypochondriasis. In: Ono Y. (Eds.) Somatoform Disorders. A Worldwide Perspective. Keio University: Springer; 1999. p.73-79.

10.Burke Jr JD, Burke KC, Couchman G. Problems in pharmacology management of somatoform disorders. In: Ono Y. (Eds.) Somatoform Disorders. A Worldwide Perspective. Keio University: Springer; 1999. p. 222-225.

11.Nomura S, Kuboki T, Yamanaka G. Approaches to the treatment of somatoform disorders in internal medicine. In: Ono Y. (Eds.) Somatoform Disorders. A Worldwide Perspective. Keio University: Springer; 1999. p. 240-245.

12.Foucault M. Naissance de la Clinique. Paris: Presses Universitaires de France; 1963.

13.Sydenham TH. Médecine pratique. Paris, 1784. Foucault M. Naissance de la Clinique. Paris: Presses Universitaires de France; 1963. p.3.

14.Frier F. Guide pour la conservation de l'homme, Grenoble, 1789. Foucault M. Naissance de la Clinique.
Paris: Presses Universitaires de France; 1963. p 7. 15.Dupont de Nemours P. Idées sur les secours à donner aux pauvres malades dans une grande ville, Paris, 1786. Foucault M. Naissance de la Clinique. Paris: Presses Universitaires de France; 1963. p.18. 16.Cabanis PJG. Observations sur les hôpitaux. Paris, 179063 Foucault M. Naissance de la Clinique. Paris: Presses Universitaires de France; 1963. p.59.

17.Girbal A. Essai sur l'esprit de la clinique médicale de Montpellier, Montpellier, 1858 Foucault M. Naissance de la Clinique. Paris: Presses Universitaires de France; 1963. p.67.

18.Cabanis PJG. la Clinique, Observations sur les hôpitaux, Paris, 1790 Foucault M. Naissance de la Clinique. Paris: Presses Universitaires de France; 1963. p.120.

19.Petit MA. Médecine du Coeur, Paris, 1781 Foucault M. Naissance de la Clinique. Paris: Presses Universitaires de France; 1963. p.88.

20.Petit MA. Discours sur la manière d'exercer la bienfaisance dans les hôpitaux, 1797 Foucault M. Naissance de la Clinique. Paris: Presses Universitaires de France; 1963. p.126.

21.Broussonnet JLV. Tableau élémentaire de la séméiotique, Montpellier, ano VI Foucault M. Naissance de la Clinique. Paris: Presses Universitaires de France; 1963. p.90.

22.Corvisart JN. Essai sur les maladies et les lésions organiques, du coeur et des gros vaisseaux, 1818. Foucault M. Naissance de la Clinique. Paris: Presses Universitaires de France; 1963.p.107,137.

23.Pine, P. La médecine clinique, Paris, 1815 Foucault M. Naissance de la Clinique. Paris: Presses Universitaires de France; 1963. p.94.

24.Bichat X. Traité des membranes, 1807 Foucault $M$. Naissance de la Clinique. Paris: Presses Universitaires 
de France; 1963. p.133.

25. Bichat $X$. Anatomie générale appliquée à la physiologie età la médecine, 1801 Foucault M. Naissance de la Clinique. Paris: Presses Universitaires de France; 1963. p.130.

26.Laënnec R. ArticleAnatomie pathologique, Dictionnaire des Sciences Médicales). Foucault M. Naissance de la Clinique. Paris: Presses Universitaires de France; 1963. p.137.

27.Broussais FJV. Examen de la doctrine, Paris. Foucault M. Naissance de la Clinique. Paris: Presses Universitaires de France; 1963. p.189.

28.Sournia JCh. Logique et morale du diagnostic, Paris, 1962 Foucault M. Naissance de la Clinique. Paris: Presses Universitaires de France; 1963. p.112. 2002; 30.

29.Laënnec R. Traité de l'auscultation médicale, Paris, 1819 Foucault M. Naissance de la Clinique. Paris: Presses Universitaires de France; 1963. p.137.

30.Cutler P. Como solucionar problemas em clínica médica. 3. ed. Rio de Janeiro: Guanabara Koogan; 1999. 31.Balint M. Le médecin, son malade et la maladie. 3. ed. Paris: Éditions Payot \& Rivages; 1996.

32.Balint M. La capacitación psicológica del médico. Barcelona: Editorial Gedisa S. A. 1* ed. 1984.

33.Southgate L. Journal of the Balint Society. 2002; 30. 34. Horder J. Journal of the Balint Society. 2002; 30. 35.A Report of the Surgeon General. Disponível em htpp://www.surgeongeneral.gov./library/mentalhealth/ chapter2/sec3.html, 1999.

36. Starfield B. Atenção primária: equilíbrio entre necessidades de saúde, serviços e tecnologia. Brasília: Ministério da Saúde, Unesco; 2002. p.291-312.

Este artigo foi adaptado da Monografia apresentada pelo autor ao Curso de Especialização em Saúde da
Família da Universidade Federal de Minas Gerais UFMG.

Orientadora: Profa. Ocirema T. Rothe-Neves

\section{Endereço para correspondência:}

Fernando A. M. Flora

Rua Santa Rita Durão, 466/1702

Belo Horizonte-MG

CEP 30140-110

\section{Endereço eletrônico:}

fernandoflora@yahoo.com.br 